\title{
Severe combined immunodeficiency and adenosine deaminase deficiency: failure of enzyme replacement therapy
}

\author{
JOHN B ZIEGLER, CHOON H LEE, MARTIN B VAN DER WEYDEN, \\ ALDO S BAGNARA, AND JOHN BEVERIDGE
}

School of Paediatrics, School of Medicine, and School of Biochemistry, University of New South Wales, and Monash University, Alfred Hospital, Melbourne, Australia

SUMMARY A first-born baby boy presented at age 3 months with persistent diarrhoea, failure to thrive, and recurrent bacterial and fungal infections. Severe combined immunodeficiency was demonstrated. A deficiency of adenosine deaminase (ADA) activity was suggested by the presence of extensive skeletal abnormalities, and the ADA activity in erythrocyte and leucocyte lysates was $<0.005 \mathrm{nmol} / \mathrm{h}$ per $\mathrm{mg}$ protein. Culture of ADA-negative peripheral blood mononuclear cells, together with purified calf ADA, did not alter the absent phytohaemagglutinin response. Treatment with immunoglobulin, pentamidine, and co-trimoxazole was started and a programme of ADA enzyme replacement, with infusions of plasma and frozen irradiated erythrocytes, was begun at age 4 months and achieved blood ADA levels in excess of $30 \mathrm{nmol} / \mathrm{h}$ per $\mathrm{mg}$ haemoglobin. Although resolution of the interstitial pneumonitis and skeletal abnormalities was observed, there was no evidence of immunological reconstitution. The patient died at age 17 months after a parainfluenza pneumonitis. Features of importance in predicting lack of benefit from enzyme replacement by erythrocyte infusion in ADA-negative severe combined immunodeficiency appear to be early clinical presentation with associated severe skeletal abnormalities, a very low level of residual ADA activity in peripheral blood mononuclear cells, and lack of effect of exogenous ADA on the absent in vitro mitogen response of ADA-negative blood mononuclear cells.

Severe combined immunodeficiency (SCID) is usually familial, often with an autosomal recessive pattern of inheritance. About half the number of children with the latter mode of inheritance are deficient in the enzyme adenosine deaminase (ADA) ${ }^{1}$ (adenosine aminohydrolase EC 3.5.4.4), and current evidence suggests a causal relationship between the enzyme deficiency and the immunopathology. ${ }^{2}$ The finding of a specific enzyme defect in SCID patients has given the opportunity to study the pathogenesis of the deficient immune status,

Prince of Wales Children's Hospital, Randwick, NSW JOHN BEVERIDGE, professor and director

Department of Immunology

JOHN B ZIEGLER, paediatric immunologist

Monash Medical School, Alfred Hospital, Victoria

MARTIN B VAN DER WEYDEN, senior lecturer in medicine

School of Biochemistry, University of New South Wales

ALDO S BAGNARA, lecturer

CHOON H LeE, 32 Castlereagh Street, Penrith, NSW 2750. consultant physician with the possibility of prenatal diagnosis and new approaches to treatment. Using frozen irradiated red blood cells from normal donors as a source of ADA, Polmar et al. ${ }^{3}$ reported correction of the immunodeficiency in one patient with ADAnegative SCID, but this in vivo immune response has not been the experience of others. ${ }^{4-5}$ Clearly the reasons for success or failure should be known so that patients can be selected for this form of treatment. We therefore report our findings on the use of frozen irradiated erythrocytes and frozen plasma as a source of ADA in the treatment of ADAnegative SCID.

\section{Methods}

Frozen blood and plasma transfusions. Frozen glycerolised type $O$ red blood cells from female donors were thawed, deglycerolised by washing with sterile saline, and irradiated with $2000 \mathrm{rad}$. Before 
transfusion between 10 and $15 \mathrm{ml} / \mathrm{kg}$ of the patient's blood was withdrawn and replaced immediately with $15 \mathrm{ml} / \mathrm{kg}$ packed cells. Normal plasma was irradiated with $2000 \mathrm{rad}$ and a dose of $15 \mathrm{ml} / \mathrm{kg}$ was given immediately after the red cell infusion. Survival of circulating donor red cells was determined using Ashby's differential agglutination technique. ${ }^{6}$

Fetal liver cell transplants. Human fetuses were obtained (from operations for tubal pregnancy or hysterectomy), and taken in sterile saline to the Prince of Wales Children's Hospital, where the liver was removed aseptically and a single cell suspension was prepared by mincing and passing it through a series of stainless steel meshes. The cells were washed 3 times and injected intraperitoneally within 3 hours of surgery.

Immunological evaluation. Serum immunoglobulins were measured by radial immunodiffusion. ${ }^{7}$ Peripheral blood mononuclear cells were isolated by Ficoll-Hypaque density gradient centrifugation. ${ }^{8}$ Lymphocyte response to phytohaemagglutinin, concanavalin $\mathbf{A}$, and pokeweed mitogen was studied in vitro in heat-inactivated normal serum using a microculture modification ${ }^{9}$ of a previously described technique. ${ }^{10}$ Calf intestine ADA obtained from Sigma (lot 45C-0404, $1350 \mathrm{IU} / \mathrm{ml}, 270 \mathrm{IU} / \mathrm{mg}$ protein) was used in appropriate cultures at a final concentration of $2 \mathrm{IU} / \mathrm{ml}$. T-lymphocytes were counted by rosetting with sheep red blood cells (E-rosettes). ${ }^{11}$ B-cells were identified as bearing complement (EAC) receptors ${ }^{12}$ and surface membrane immunoglobulin. ${ }^{13}$

Determination of ADA activity in red blood cells and leucocytes. ADA activity of red blood cells and leucocytes was determined by radioisotopic assay as previously described. ${ }^{14}$ The ADA assay used to monitor the transfusion programme has also been described. ${ }^{15}$

Plasma adenosine. Plasma adenosine was measured in neutralised perchloric acid extracts of plasma with high pressure liquid chromatography (HPLC) using a Partisil 10 SCX cation exchange column. Elution was performed with $50 \mathrm{mmol} / 1 \mathrm{NH} 4 \mathrm{H} 2 \mathrm{PO} 4$ buffer ( $\mathrm{pH} 3.0)$ at a rate of $0.5 \mathrm{ml} / \mathrm{min}$ and adenosine detected at $254 \mathrm{~nm}$ and quantified using an Autolab integrator (full-scale deflection 0.02) with peak area calibration curves constructed from standard adenosine solutions.

Erythrocyte adenine nucleotides. Erythrocyte adenosine triphosphate (ATP) was measured enzymatically using Sigma ATP kit. Since publication of the report implicating 2 deoxyadenosine triphosphate (2dATP) as a potentially toxic metabolite, ${ }^{16}$ red cells obtained from a patient before transfusion were stored in liquid nitrogen for 18 months and analysed for their nucleotide profile with HPLC after perchloric acid extraction and subsequent neutralisation. An Altex model 110 system fitted with a Partisil-10 SAX anion exchange column was used. Elution was performed at a flow rate of $1.2 \mathrm{ml} / \mathrm{min}$ using a 20 minute concave gradient from 10 to $500 \mathrm{mmol} / \mathrm{l}$ NH4H2PO4 buffer (pH 4.0). Adenine nucleotide peaks were detected at $254 \mathrm{~nm}$ and quantified using an Autolab integrator with peak area calibration curves constructed from standard nucleotide solutions.

\section{Case report}

A white boy was born on 10 November 1976 after an uncomplicated first pregnancy. Birthweight was $3.6 \mathrm{~kg}$. In the first few days of life several large pustular lesions on limbs grew Staphylococcus aureus and purulent aural discharge was noted. Diarrhoea and cough began at age 2 weeks and persisted until he was admitted to hospital. $X$-rays at age 10 weeks showed absent thymic shadow, evidence of interstitial pneumonitis, and short ribs with flared anterior ends.

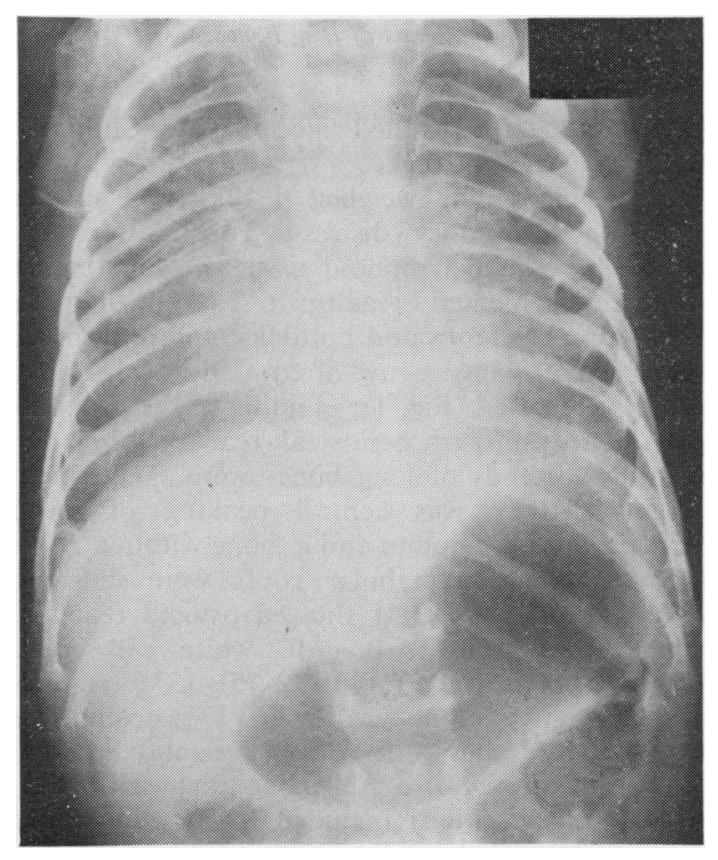

Fig. $1 X$-ray at age 3 months. Note clouded lung fields, absent thymic shadow, and flared anterior ends of ribs. 


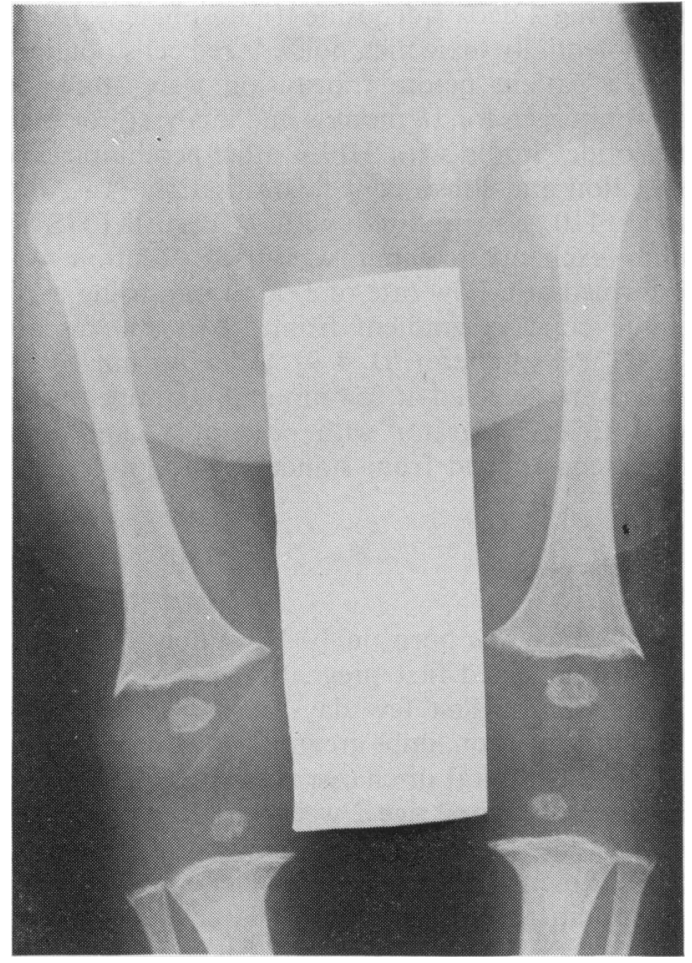

Fig. $2 X$-ray at age 3 months. Note widened and irregular metaphyseal ends of long bones.

He was transferred to the Prince of Wales Children's Hospital at age 14 weeks.

On admission he weighed $4.2 \mathrm{~kg}$ and showed moderate respiratory distress. Tonsils were not visible, peripheral lymphoid tissue was impalpable. Several depigmented areas up to $2 \mathrm{~cm}$ in diameter were seen over limbs and buttocks, and oral thrush was present. The $x$-ray abnormalities described above were noted (Fig. 1); in addition the proximal long bones showed periosteal reaction (Fig. 2); metaphyseal ends of long bones were splayed and irregular; there was central beaking of lower thoracic vertebral bodies and a 'bone within a bone' appearance, the acetabular roofs were flat and irregular, and iliac crest showed osteoid reaction. Haemoglobin was $15.0 \mathrm{~g} / \mathrm{dl}$, white cell count $4.3 \times 10^{9} / 1,64 \%$ neutrophils $(2.75), 13 \%$ lymphocytes $(0 \cdot 56), 4 \%$ monocytes $(0 \cdot 17), 17 \%$ eosinophils $(0.73)$, and $2 \%$ basophils $(0.09)$. Despite abnormal platelet function in vitro, ${ }^{15}$ bleeding time was normal. Normal investigations included urinary metabolic screen and sweat electrolytes. Immunological studies (see Results) indicated SCID. ADA deficiency, suggested by the $x$-rays, was confirmed by analysis
Table 1 ADA activity in erythrocyte and leucocyte preparations in the child with severe combined immunodeficiency and his parents

\begin{tabular}{lll}
\hline & \multicolumn{2}{l}{ Activity $($ nmol/h per mg protein) } \\
\cline { 2 - 3 } & Haemolysate & Leucocytes \\
\hline Patient & $<0.005$ & $<0 \cdot 005$ \\
Mother & 28 & 202 \\
Father & 35 & 300 \\
Normal & $63 \pm 24(\mathrm{n}=50)$ & $750 \pm 280(\mathrm{n}=23)$ \\
\hline
\end{tabular}

of red blood cells and leucocytes, and both parents were found to be heterozygotes (Table 1).

With a diagnosis thus made of SCID with probable Pneumocystis carinii pneumonitis, treatment was begun with pentamidine isethionate (for 14 days), co-trimoxazole, oral nystatin, and gammaglobulin. As the infant had no siblings, it was decided to attempt immunological reconstitution with frozen glycerolated red blood cells and plasma (see Methods). Some modest clinical improvement took place. Diarrhoea resolved, respiratory distress settled, lung fields cleared, and there was a moderate weight gain. Maximum weight, after 5 months of treatment, was $6.4 \mathrm{~kg}$ at age 9 months (3rd centile). No evidence of immunological reconstitution was obtained although (Fig. 3) modest rises in lymphocyte counts, considered clinically insignificant, followed the first 3 infusions. $X$-ray abnormalities improved remarkably and by age 9 months (after 5 months of treatment), ribs had lengthened with resolution of flaring, and long bone metaphyses were considered to have become normal in appearance (Fig. 4). The child had grown $9 \mathrm{~cm}$ in length during the preceding 6 months.

At age 9 months watery diarrhoea started which persisted until death at 17 months. This was attributed to a persistent rotavirus noted ultrastructurally in the gut epithelium and in repeated stool specimens (J D Mitchell, L Sosula, M Cloonan, and $\mathbf{J} B$ Ziegler, in preparation). In view of failure of erythrocyte infusions and lack of a bone marrow donor, attempts were made to produce immunological reconstitution using fetal liver cells at ages 12,13 , and 16 months but these were unsuccessful. There was progressive deterioration in the state of respiration after a parainfluenza virus had been isolated from the sputum at age 14 months; the patient died aged 17 months in a country hospital.

At necropsy, parainfluenza virus was cultured from lungs which were grossly consolidated. Lymphoid tissue was essentially undetected. A small amount of thymus tissue was found and showed absence of Hassall's corpuscles, scanty lymphocytes, and absent cortico-medullary differentiation. Small epithelial rosettes were evident. Blood vessels were not prominent. 


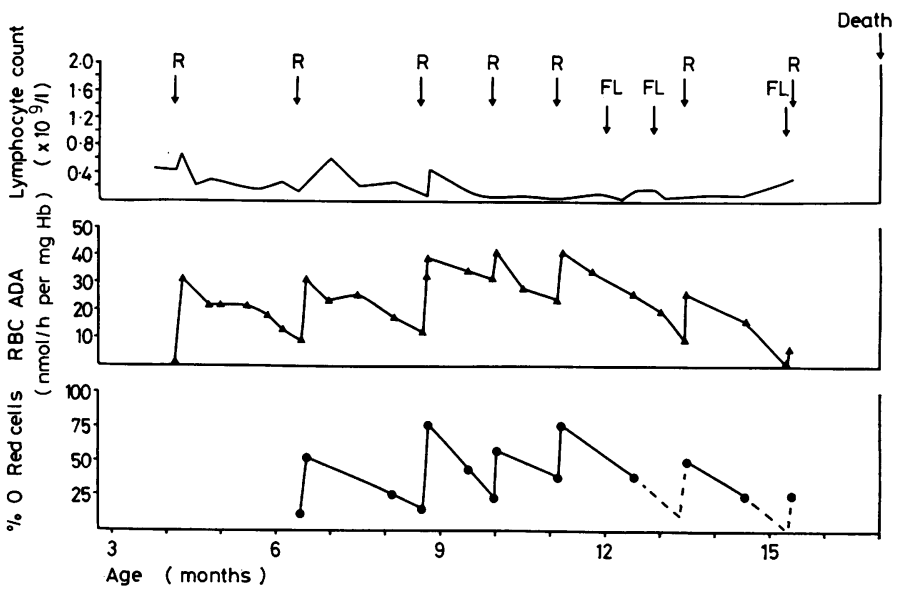

Fig. 3 Flow chart showing time of erythrocyte and plasma infusions $(R)$ and fetal liver transplants (FL). Panels show absolute lymphocyte counts, erythrocyte adenosine deaminase (ADA) levels, and percentage of $O$ red cells in the patient.

\section{Results}

Immunological studies. Immunological data on presentation at age 3 months are given in Table 2 . To evaluate the effect of exogenous ADA on the phytohaemagglutinin response in vitro, an experiment was performed during the erythrocyte infusion programme immediately before an infusion when circulating exogenous ADA levels were at a minimum. The addition of $2 \mathrm{IU} / \mathrm{ml}$ calf ADA had no effect on the depressed phytohaemagglutinin response of the patient (data not shown).

Effect of erythrocyte infusions. The timing of red cell infusions, their effect on red cell ADA levels (together with the establishment of red blood cell

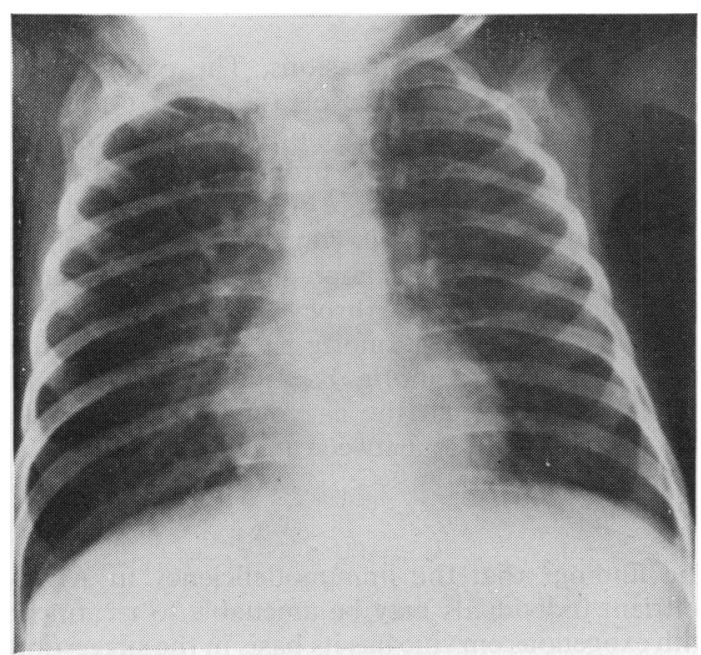

(a)

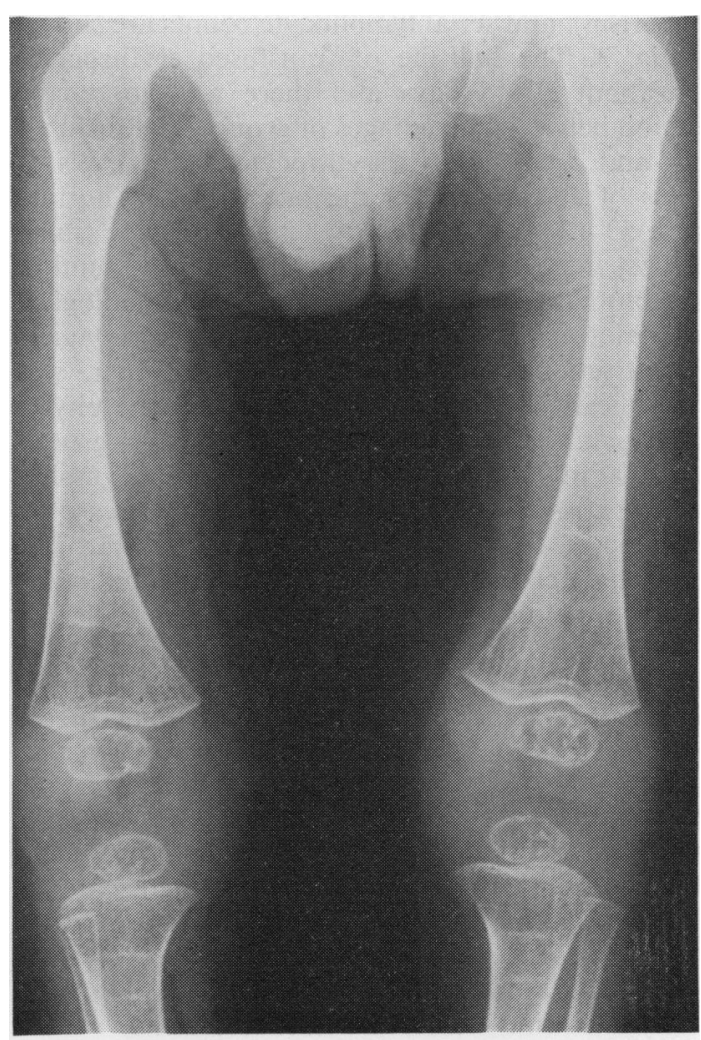

(b)

Fig. $4 X$-rays (a) chest at age 9 months, (b) lower limbs at 16 months. Note improvement in rib and long bone deformities. 
Table 2 Serial immunological studies in an ADA-negative child undergoing erythrocyte infusion programme

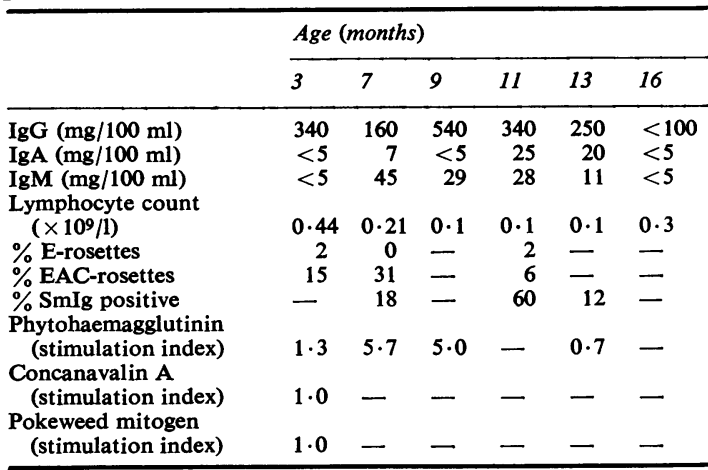

$\mathbf{E}=$ sheep red blood cells, $\mathbf{E A C}=\mathbf{E}$ with antibody and complement, $\mathrm{SmIg}=$ surface membrane immunoglobulin.

chimerism), and serial lymphocyte counts are shown in Fig. 3. The half-life of transfused erythrocytes was about 30-45 days and there was good correlation between percentages of group $O$ transfused cells and ADA levels. Erythrocyte ADA levels in excess of $30 \mathrm{nmol} / \mathrm{h}$ per $\mathrm{mg}$ haemoglobin (normal range 53-120) were regularly achieved by the transfusions, these levels being similar to those found in asymptomatic heterozygotes. ${ }^{17}$ Serial immunological evaluation is shown in Table 2. Immunological reconstitution was not obtained although there was a significant increase in IgM levels and the phytohaemagglutinin stimulation index (usually greater than 100 in control subjects) rose to $5 \cdot 7$. Lymphopenia persisted although a transient increase in lymphocyte count followed the first 3 erythrocyte infusions. Cells bearing surface immunoglobulin and complement receptors comprised the majority of circulating lymphocytes but remained reduced in absolute numbers. Marked T-cell lymphopenia persisted. No antibody response to tetanus toxoid was detected after 3 injections of triple antigen.

Plasma adenosine. Plasma adenosine was detected in elution fraction at about 600 seconds using the HPLC system described above. It was quantitated at $4 \mu \mathrm{mol} / 1$ in the original plasma and at 3 and 1 $\mu \mathrm{mol} / 1$ five weeks after the second and third erythrocyte transfusions respectively. The compound 2 deoxyadenosine was not detected in plasma.

Erythrocyte adenine nucleotides. Erythrocyte ATP, determined enzymatically (Sigma kit) before the first transfusion, was $7.0 \mu \mathrm{mol} / \mathrm{g}$ haemoglobin (normal range 3.6 to $4 \cdot 5$ ). Erythrocyte ATP was also determined 5 weeks after the second and third erythrocyte transfusions and was found to be $5.4 \mu \mathrm{mol} / \mathrm{g}$

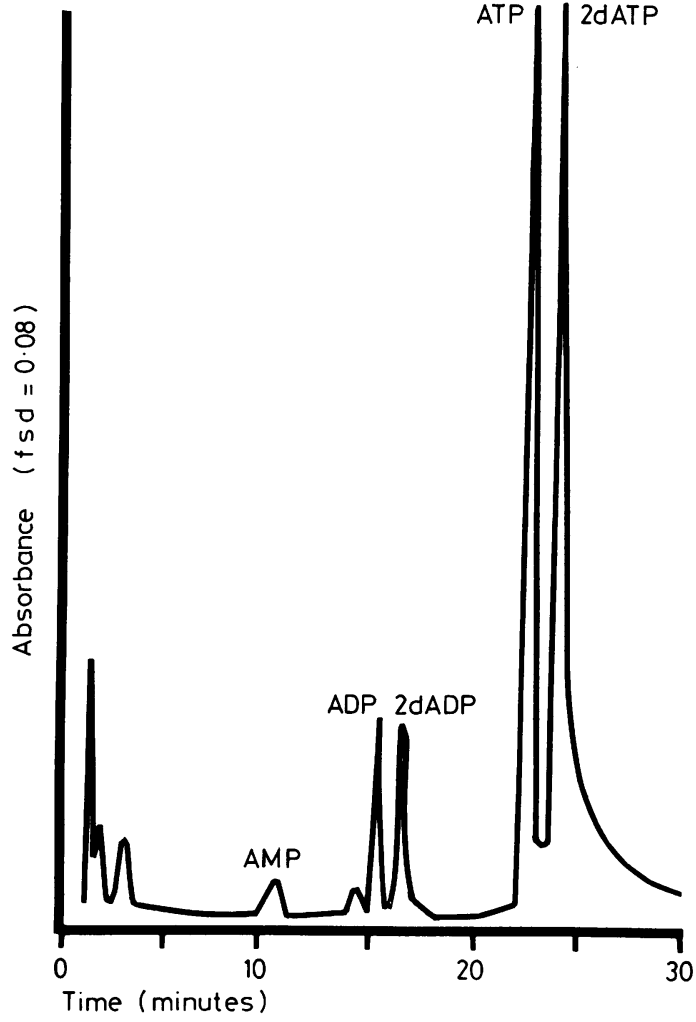

Fig. 5 High pressure liquid chromatography profile of extracts of patient's red cells before first erythrocyte infusion exhibiting the greatly increased levels of 2dADP and 2dATP not observed in ADA-positive erythrocytes.

haemoglobin on both occasions. The parents had normal erythrocyte ATP levels (father, $3.6 \mu \mathrm{mol} / \mathrm{g}$ haemoglobin; mother, $4 \cdot 1 \mu \mathrm{mol} / \mathrm{g}$ haemoglobin).

Analysis of nucleotide profiles by HPLC in erythrocytes obtained before treatment showed the presence of 2dATP in high concentration, as well as 2dADP (Fig. 5). The compound 2dATP is not a constituent of normal erythrocytes. On quantitation, the ATP level was $3.4 \mu \mathrm{mol} / \mathrm{g}$ haemoglobin and the 2dATP level $4.5 \mu \mathrm{mol} / \mathrm{g}$ haemoglobin. It would therefore appear that the enzymatic determination does not differentiate between ATP and 2dATP.

\section{Discussion}

The finding ${ }^{3}$ that the immunodeficiency in ADAdeficient individuals may be amenable to treatment with exogenous enzyme has its basis in the suggestion that the immune disturbance is secondary to the 
accumulation of either adenosine or deoxyadenosine and the attending metabolic consequences, such as increased intracellular 2dATP levels, as noted in this patient and previously reported. ${ }^{5} 16$

Although this form of treatment was successful in another patient with ADA-negative $\mathrm{SCID}^{18}$ our findings and those reported by others ${ }^{419}$ are less encouraging. Clearly heterogeneity of clinical response exists, and the present findings together with those reported by others have shown that the extent of residual ADA activity in peripheral blood mononuclear cells and the effect of ADA on the mitogenic responsiveness of ADA-negative lymphocytes may reasonably predict the clinical outcome of enzyme replacement in a patient with ADAnegative SCID. The peripheral blood mononuclear ADA activity in the 2 patients who exhibited beneficial response to replacement therapy is reputedly 6 and $8 \%$ that of normal ${ }^{318}$ whereas that noted in our patient, or others refractory to this treatment, has been undetectable $-<1$ and $<4 \%$ respectively. ${ }^{4-5}$ Likewise the lack of an appreciable effect of exogenous ADA on the markedly reduced mitogenic responsiveness of ADA-negative lymphocytes as noted in our patient had been the experience of others ${ }^{4}$ and clearly contrasts with the residual mitogenic responsiveness ${ }^{18}$ and its augmentation by exogenous ADA of lymphocytes ${ }^{20}$ of those patients responsive to enzyme replacement therapy.

These findings indicate that the severity of the metabolic defect appears to be singly the most important determinant of the clinical course, a suggestion attested to by the early onset of symptoms, the extent of bony and thymic abnormalities, and failure of exogenous ADA replacement therapy noted in our patient.

We thank Dr D Carseldine for referring the patient.

This study was supported in part by the National Health and Medical Research Council of Australia.

\section{References}

1 Giblett E R, Anderson J E, Cohen F, Pollara B, Meuwissen H J. Adenosine deaminase deficiency in two patients with severely impaired cellular immunity. Lancet 1972; ii: 1067-9.

2 Meuwissen H J, Pollara B, Pickering R J. Combined immunodeficiency disease associated with adenosine deaminase deficiency. J Pediatr 1975; 86: 169-81.

3 Polmar S H, Stern R C, Schwartz A L, Wetzler E M, Chase P A, Hirschhorn R. Enzyme replacement therapy for adenosine deaminase deficiency and severe combined immunodeficiency. $N$ Engl J Med 1976; 295: 1337-43.

- Schmalstieg F C, Mills G C, Nelson J A, May L T, Goldman A S, Goldblum R M. Limited effect of erythrocyte and plasma infusions in adenosine deaminase deficiency. J Pediatr 1978; 93: 597-603.
5 Coleman M S, Donofrio J, Hutton, J J, et al. Identification and quantitation of adenine deoxynucleotides in erythrocytes of a patient with adenosine deaminase deficiency and severe combined immunodeficiency. $J$ Biol Chem 1978; 253: 1619-26.

- Dacie J V, Lewis S M, eds. Practical haematology. 4th edition. London: Churchill, 1968: 374-6.

7 Mancini G, Carbonera A O, Heremans J F. Immunochemical quantitation of antigens by single radial immunodiffusion. Immunochemistry 1965; 2 : 235-54.

8 Boyum A. A one stage procedure for isolation of granulocytes and lymphocytes from human blood. Scand J Clin Lab Invest 1968; 21 : Supplement 97, 51-76.

- Cooper D A, Petts V, Luckhurst E, Biggs J C, Penny R. $T$ and $B$ cell populations in blood and lymph node in lymphoproliferative disease. Br J Cancer 1975; 31 : 550-8.

10 Ziegler J B, Hansen P, Penny R. Intrinsic lymphocyte defect in Hodgkin's disease: analysis of the phytohemagglutinin dose-response. Clin Immunol Immunopathol 1975; 3: 451-60.

11 Jondal M, Holm G, Wigzell H. Surface markers on human $T$ and B lymphocytes. I. A large population of lymphocytes forming non-immune rosettes with sheep red blood cells. J Exp Med 1972; 136: 207-15.

12 Bianco C R P, Patrick R, Nussenzweig V. A population of lymphocytes bearing a membrane receptor for antigenantibody- complement complexes. I. Separation and characterization.J Exp Med 1970; 132: 702-20.

13 Papamichail M, Brown J C, Holborow E J. Immunoglobulins on the surface of human lymphocytes. Lancet 1971; ii: 850-2.

14 Van der Weyden M B, Bailey L. A micromethod for determining adenosine deaminase and purine nucleotide phosphorylase activity in cells from human peripheral blood. Clin Chim Acta 1978; 82: 179-84.

15 Lee C H, Evans S P, Rozenberg M C, Bagnara A, Ziegler $\mathrm{J} B$, Van der Weyden $\mathrm{M}$ B. In vitro platelet abnormality in adenosine deaminase deficiency and severe combined immunodeficiency. Blood 1979; 53: 465-71.

16 Cohen A, Hirschhorn R, Horowitz S D, et al. Deoxyadenosine triphosphate as a potentially toxic metabolite in adenosine deaminase deficiency. Proc Natl Acad Sci USA 1978; 75 : 472-6.

17 Lee C H, Rozenberg M C, Ziegler J B. Family study on the kindred of an adenosine deaminase deficient child with severe combined immunodeficiency. Aust NZ J Med 1979;9: 530-3.

18 Uberti J, Lightbody J J, Wolf J W, Anderson J A, Reid $R$ H, Johnson $R M$. The effect of adenosine on mitogenesis of ADA-deficient lymphocytes. Clin Immunol Immunopathol 1978; 10: 446-58.

19 Donofrio J, Coleman M S, Hutton J J, Daoud A, Lampkin B, Dyminski J. Overproduction of adenine deoxynucleosides and deoxynucleotides in adenosine deaminase deficiency with severe combined immunodeficiency disease. J Clin Invest 1978; 62: 884-7.

20 Polmar S H, Wetzler E M, Stern R C, Hirschhorn R. Restoration of in vitro lymphocyte response with exogenous adenosine deaminase in a patient with severe combined immunodeficiency. Lancet 1975; ii: 743-6.

Correspondence to Dr John B Ziegler, Department of Immunology, Prince ofWales Children's Hospital, High Street, Randwick, NSW 2031, Australia.

Received 26 June 1979 